\title{
PROGRAMA DE APRIMORAMENTO PARA PROFISSIONAIS DA INFORMAÇÃO EM CIÊNCIAS DA SAÚDE
}

\section{Cláudia Araujo Martins}

\section{Resumo:}

Em Ciência da Informação, áreas de atuação distintas exigem profissionais distintos. Se por um lado, a formação generalista do bibliotecário lhe garante um amplo mercado de trabalho, por outro, a falta de especialização pode ser um obstáculo para uma vaga de emprego. Áreas como as Ciências da Saúde exigem competências não desenvolvidas na graduação, com raras exceções. Com o intuito de qualificar, capacitar e suprir defasagens dos cursos de Biblioteconomia e Ciência da Informação foi criado o Programa de Aprimoramento em Documentação e Informação em Ciências da Saúde, um curso de pós-graduação lato sensu, que atualmente encontra-se em fase de implantação e avaliação.

\section{Palavras-Chave:}

Bibliotecário; Educação continuada; Atuação profissional; Ciências da saúde

\section{IMPROVEMENT PROGRAM FOR HEALTH SCIENCES INFORMATION PROFESSIONALS}

\begin{abstract}
:
In Information Science different fields of work seeks for different professional backgrounds. If, on the one hand, the generalist background of the librarian assures him/her a broad labor market, on the other hand, the unskilled professionals may find difficulty to fill a vacant position. With a few exceptions, fields such as Health Sciences require a competence model not achieved in undergraduate courses. The Improvement Program in Documentation and Information on Health Sciences was implemented with the purpose to provide qualification and professional skills, and to fill the gap of academic courses in Library Science and Information Science. Currently, this program is in the process of being settled and evaluated.
\end{abstract}

\section{Keywords:}

Librarian; Continuing education; Professional performance; Health sciences 


\section{INTRODUÇÃO}

Diversos autores têm como objeto de estudo a relevância e as peculiaridades da atividade bibliotecária em diferentes áreas do conhecimento. É sabido que nos últimos anos o mercado de trabalho ampliou-se e que as competências exigidas de um profissional da informação são diferenciadas de acordo com a área escolhida (VALENTIM, 2000a; CRUZ, 2001; BUENO; BLATTMANN, 2005; PINTO; IOCHIDA, 2005; BERAQUET et al., 2006).

Valentim (2000b, p. 4) aponta que o profissional da informação deve "ser mais observador, empreendedor, atuante, flexível, dinâmico, ousado, integrador, proativo e principalmente voltado para o futuro” para marcar seu território de atuação nessa nova era. A autora categoriza as novas competências bibliotecárias em quatro linhas distintas, mas co-relacionadas: competência em comunicação e expressão, competências técnicocientíficas, competências gerenciais e competências sociais e políticas. (VALENTIM, 2000a)

No que diz respeito ao desenvolvimento de suas competências, em muitos casos, o aluno de Biblioteconomia cursa uma graduação orientada para a prática profissional em campos tradicionais, de acordo com alguns pesquisadores da área. Esses autores demonstram incompatibilidades entre os requisitos mercadológicos atuais do bibliotecário e o currículo de algumas universidades, e são unânimes em afirmar a necessidade de educação continuada para uma atuação mais eficiente dos profissionais da informação (BELLUZZO, 1995; ARRUDA; MARTELETO; SOUZA, 2000; FERREIRA, 2003; CASTRO; RIBEIRO, 2004; PINTO; IOCHIDA, 2005).

Porém, todos eles à sua maneira enfatizam a importância da graduação como alicerce para a formação profissional e como principal promotora de conhecimentos essenciais que sedimentarão os elos entre a teoria e a práxis, como expõe Valentim (2000a).

Como forma de suprir possíveis defasagens, alguns cursos de graduação estão repensando seus currículos (BARBOSA, 1998; BARBOSA et al., 2000; MAIA; ALBUQUERQUE, 2006). No entanto, nesse cenário em evolução, ainda existem lacunas entre a formação do profissional e a real necessidade de determinadas instituições, que buscam mão-de-obra qualificada (SOUZA, 1996; BARBOSA, 1998; 
SILVA; CUNHA, 2002; TARAPANOFF; SUAIDEN; OLIVEIRA, 2002, MEDEIROS, 2006).

Em Ciências da Saúde, as expectativas informacionais dos usuários, especialmente os pesquisadores, exigem a atuação de um bibliotecário especializado, que domine o uso de fontes de informação e que seja mediador do aprendizado dessas fontes, dentre outras características (TARAPANOFF; SUAIDEN; OLIVEIRA, 2004; BERAQUET et al., 2006; MARTINS; KAVANAMI; FANANI, 2007).

Dados divulgados pela Revista Pesquisa FAPESP informam que, em 2005, a produção científica nacional foi “responsável por 1,8\% de todos os artigos publicados em periódicos científicos indexados na base de dados do ISI (Instituto de Informação Científica), índice que mede a atividade de pesquisa no mundo” (MAIS UM DEGRAU, 2006).

Se nos restringirmos apenas ao volume de informações geradas pela área médica, já possuímos justificativa suficiente para a obrigatoriedade de capacitação do bibliotecário da saúde, uma vez que a área é considerada a principal divulgadora de informação científica brasileira, com 19,7\% do total das publicações (MAIS UM DEGRAU, 2006).

Tais dados são confirmados se fizermos rápida busca pelas principais bases de dados bibliográficas utilizadas na saúde. São elas: PubMed, EMBASE, SCOPUS, Web of Science e SciELO.

As duas primeiras são especializadas em indexar artigos da área biomédica e cada uma contém, respectivamente, 17 milhões e 18 milhões de citações, sendo que aproximadamente 2.000 novos registros são incorporados às bases diariamente (UNITED STATES, 2008; ELSEVIER, 2008a). As outras três são bases multidisciplinares. No entanto, a representatividade da área biomédica é de 58\% dos títulos totais indexados na SCOPUS, 73\% na Web of Science e $46 \%$ na SciELO. (ELSEVIER, 2008b; BRASIL, 2008; FAPESP, 2008) 
Por essa razão, o Serviço de Biblioteca e Documentação Científica "Prof ${ }^{\circ}$ Dr. José Victor Maniglia” (SBDC), da Faculdade de Medicina de São José do Rio Preto (FAMERP), em parceria com a Comissão de Aprimoramento e Aperfeiçoamento da FAMERP (COAPRIMO) e a Fundação do Desenvolvimento Administrativo (FUNDAP) decidiu criar um programa de aprimoramento que preparasse o profissional da informação para atuação em saúde, auxiliando no desenvolvimento de suas competências.

O presente artigo objetiva divulgar esse Programa de Aprimoramento em Informação e Documentação em Ciências da Saúde e despertar o interesse de profissionais da informação que buscam aperfeiçoamento para atuação em saúde. Além disso, pretendese arregimentar possíveis candidatos ao aprimoramento.

\section{A BIBLIOTECA DA FAMERP}

O Serviço de Biblioteca e Documentação Científica “Prof. Dr. José Victor Maniglia”, da Faculdade de Medicina de São José do Rio Preto, disponibiliza informações especializadas nas áreas de Ciências Biológicas e da Saúde à comunidade acadêmica e à comunidade externa em geral.

A Faculdade tem como missão formar médicos e enfermeiros e, além disso, pósgraduar, informar e manter atualizados os profissionais da saúde que prestam seu conhecimento e seu serviço à comunidade.

Em vista disto, podemos afirmar que a missão da Biblioteca da FAMERP é “coletar e tratar a informação em Ciências Biológicas e da Saúde, de forma a disponibilizá-la e disseminá-la à comunidade acadêmica para fins de ensino, pesquisa e extensão”.

Atualmente a Biblioteca funciona de segunda a sexta-feira, das 07h00 às 21h00, aos sábados, das $08 \mathrm{~h} 00$ às $13 \mathrm{~h} 00$, e ocupa $1.487,57 \mathrm{~m}^{2}$.

Os serviços oferecidos pela Biblioteca são: acervo aberto e informatizado, atendimento à comunidade interna e externa, empréstimo domiciliar de material bibliográfico, exposição de fascículos dos periódicos mais recentes, terminais de computadores 
conectados à Internet, acesso à base de dados eletrônicos, textuais e referenciais, levantamento bibliográfico do acervo local e em bases de dados nacionais e internacionais na área de Ciências da Saúde e áreas afins, comutação bibliográfica, reprografia, murais informativos, orientação bibliográfica, normalização de documentos e referências bibliográficas e visitas orientadas.

Seu acervo é composto por livros, fascículos de periódicos, teses, dissertações, monografias, slides, CD’S-ROM, vídeos, dentre outros.

Sua clientela é formada por graduandos dos cursos de Medicina e Enfermagem, pósgraduandos lato e stricto sensu, docentes, residentes, aprimorandos, aperfeiçoandos, funcionários da FAMERP e do Hospital de Base, e a comunidade externa em geral. Totalizando cerca de 6.000 usuários potenciais.

\section{O PAP-FAMERP}

O Programa de Aprimoramento Profissional (PAP) - Documentação e Informação em Ciências da Saúde da FAMERP formou seu primeiro bibliotecário em 2008. Apesar de ter sido criado em 2001, nos dois primeiros anos não houve candidato. Nos dois anos subseqüentes o concurso público não foi realizado por motivos internos e no ano seguinte de sua reabertura não houve público interessado em fazê-lo.

As razões para o desinteresse dos profissionais em se candidatar, com base em entrevista informal com alguns graduandos, variam entre o baixo valor da bolsa de estudos se comparado ao piso salarial de um bibliotecário, a distância da instituição em relação às cidades que possuem cursos de graduação em Biblioteconomia, desconhecimento sobre a existência do programa ocasionado pela falta de divulgação eficaz, ou ainda, a preferência por outras áreas de especialização.

\subsection{Caracterização}

O PAP - Documentação e Informação em Ciências da Saúde é realizado com o apoio da FUNDAP, responsável pela autorização, normatização, avaliação e concessão de bolsas de estudos e gerenciado pela COAPRIMO.

(c) Revista Digital de Biblioteconomia e Ciência da Informação,Campinas, v.6, n. 1, p. 48-60, jul/dez. 2008- ISSN: 1678-765X. 
Destina-se à formação complementar, em nível de pós-graduação, de bibliotecários que se interessam em atuar em instituições de Saúde, por meio de trabalho supervisionado pelo Serviço de Biblioteca da FAMERP.

O candidato ao PAP deve possuir formação superior reconhecida pelo Ministério da Educação e registro no Conselho Regional de Biblioteconomia.

A seleção de candidatos é constituída por duas fases, a primeira com a aplicação de provas múltipla escolha e dissertativa sobre conhecimentos específicos, a segunda com entrevista e análise de currículo.

O curso possui duração de um ano, com carga horária semanal de 40h, sendo 80\% constituído por práticas profissionais e $20 \%$ por aulas teóricas. A carga horária anual deve conter 1.760 horas no mínimo e no máximo 1.920 horas.

Da carga horária teórica, ao menos 40h devem ser compostas por disciplinas relacionadas às Políticas Públicas de Saúde/SUS, contextualizando a instituição no sistema de saúde.

O restante do conteúdo teórico é reservado às disciplinas ministradas por profissionais da instituição ou docentes convidados. São elas:

- Metodologia de pesquisa científica;

- Estatística aplicada à saúde;

- História da saúde;

- Didática;

- Ética;

- Inglês instrumental;

- Normatização de trabalhos acadêmicos;

- Pesquisa bibliográfica em saúde;

- Terminologia em saúde;

- Disseminação seletiva da informação em saúde;

- Orientação e estudo de usuários;

- Estratégias de busca em bases de dados textuais e referenciais.

(c) Revista Digital de Biblioteconomia e Ciência da Informação,Campinas, v.6, n. 1, p. 48-60, jul/dez. 2008- ISSN: 1678-765X. 
As práticas profissionais são focadas nas atividades cotidianas realizadas pela Biblioteca da FAMERP e permeadas pelas funções atribuídas a ela: coletar, processar, armazenar, preservar, recuperar e disseminar a informação (OSÓRIO; ALFANO, 1994).

Considerando apenas as funções técnicas acima mencionadas, o aprimorando desenvolve uma série de tarefas, descritas a seguir:

- Aquisição de material impresso e eletrônico;

- Catalogação utilizando o Código AACR2 (Código de Catalogação AngloAmericano) e o MARC 21 (Formato de Catalogação Legível por Máquina);

- Classificação de assuntos utilizando a NLM Classification (Classificação da Biblioteca Nacional de Medicina dos Estados Unidos);

- Classificação de autor utilizando a tabela PHA;

- Indexação de assuntos segundo a Terminologia em Saúde, chamada DeCS (Descritores em Ciências da Saúde), vocabulário controlado utilizado para descrever os assuntos principais da obra;

- Preparo técnico do material para ser enviado ao acervo, tais como: carimbagem e etiquetagem;

- Recuperação bibliográfica em bases de dados e portais de Ciências da Saúde;

- Comutação bibliográfica de materiais no Brasil e exterior;

- Atendimento ao público, prestando informações, normatizando trabalhos acadêmicos de acordo com as normas da ABNT (Associação Brasileira de Normas Técnicas) ou Estilo Vancouver e orientando pesquisas bibliográficas;

- Disseminação Seletiva da Informação.

Por ser um curso de pós-graduação a produção de conhecimento é exigida do aprimorando, que deve participar de eventos científicos e encaminhar artigos para periódicos especializados.

Ao final do programa o aluno apresenta um trabalho de conclusão de curso baseado em projeto desenvolvido durante o aprimoramento, como parte dos requisitos para obter o certificado ao término do curso. O cumprimento da carga horária teórica-prática e a 
realização de avaliações consistem nos outros requisitos para a formação do profissional em questão.

\subsection{Objetivos do PAP}

- Capacitar o participante para uma atuação qualificada e diferenciada na área objeto do Programa de Aprimoramento, promovendo o aperfeiçoamento do desempenho profissional, por meio da oportunidade de acesso a novos conhecimentos teóricos e ênfase nas práticas específicas;

- Estimular nos aprimorandos o desenvolvimento de uma visão crítica e abrangente do Sistema Único de Saúde, orientando sua ação para melhoria das condições de saúde da população usuária do SUS;

- Aprimorar o processo de formação dos participantes, considerando as diretrizes e princípios do SUS de modo a desenvolver uma compreensão ampla e integrada das diferentes ações e processos de trabalho da instituição participante do programa. (FUNDAP, 2006)

\subsection{Objetivos do PAP- Documentação e Informação em Ciências da Saúde}

O objetivo principal do programa da FAMERP é preparar profissionais para atendimento diferenciado ao público que presta cuidados de saúde no que diz respeito à recuperação de informação científica.

Os objetivos secundários são:

- Complementar a formação universitária em relação aos aspectos da prática profissional não abordados na graduação;

- Desenvolver habilidades informacionais para a realização de pesquisas bibliográficas junto à comunidade usuária da Biblioteca;

- Enfatizar uma visão global e integrada do indivíduo;

- Desenvolver habilidades para a realização do trabalho interdisciplinar;

- Favorecer uma atuação profissional ética; 
- Desenvolver uma postura profissional que favoreça os interesses dos usuários da Biblioteca e que permita o desenvolvimento de uma identidade profissional do bibliotecário como membro das equipes interdisciplinares e do sistema de saúde.

\subsection{Perfil desejado do candidato}

- Conhecimentos básicos de informática e de recursos de busca de informações por meio eletrônico;

- Interesse por realizar buscas bibliográficas em saúde;

- Habilidade de trabalho interdisciplinar e em grupo;

- Bom nível de conhecimentos gerais em Ciência da Informação e específicos em Informação em saúde;

- Disponibilidade de horário para participar das atividades programadas;

- Espírito de liderança, apresentação verbal e pessoal adequadas.

\section{CONCLUSÃO}

O PAP-Documentação e Informação em Ciências da Saúde, ao formar seu primeiro bibliotecário em 2008, obteve como feed-back uma avaliação muito satisfatória. Seu aprimorando, empregado por uma instituição de ensino particular antes mesmo do término do programa, o apontou como fundamental para a aprendizagem de conhecimentos específicos sobre a área da saúde e, surpreendentemente, para a ampliação de seus conhecimentos básicos adquiridos na faculdade, em razão da oportunidade da práxis.

Em entrevista de encerramento de curso, o bibliotecário aprimorando informou que se sentia apto, confiante e competente para administrar bibliotecas da saúde e atender às demandas informacionais de seu público, condição não alcançada ao término de sua graduação.

Dada a sua relevância para o aprimoramento do trabalho especializado em informação em saúde, o PAP deve ser divulgado entre nossos pares. Assim, continuamos trabalhando para que não seja descredenciado por falta de candidatos, pois acreditamos 
na formação complementar que o programa pode oferecer, no valor que pode agregar a formação do profissional e, conseqüentemente, no diferencial de sua mão-de-obra.

\section{REFERÊNCIAS}

ARRUDA, M. C. C.; MARTELETO, R. M.; SOUZA, D. B. Educação, trabalho e o delineamento de novos perfis profissionais: o bibliotecário em questão. Ciência da Informação, Brasília, v. 29, n. 3, p. 14-24, set./dez. 2000.

BARBOSA, R. R. Perspectivas profissionais e educacionais em biblioteconomia e ciência da informação. Ciência da Informação, Brasília, v. 27, n. 1, p. 53-60, jan./abr. 1998.

. et al. Novo nome e novo paradigma: da biblioteconomia à ciência da informação. Perspectivas em Ciência da Informação, Belo Horizonte, v. 5, n. especial, p. 81-91, jan./jun. 2000.

BELLUZZO, R. C. B. Da capacitação de recursos humanos à gestão da qualidade em bibliotecas universitárias: paradigma teórico-prático para ambiente de serviço de referência e informação. 1995. 259f. Tese (Doutorado) - Escola de Comunicação e Artes, Universidade de São Paulo, São Paulo, 1995.

BERAQUET, V. S. M. et al. Desenvolvimento do profissional da informação para atuar em saúde: identificação de competências. Revista Digital de Biblioteconomia e Ciência da Informação, Campinas, v. 3, n. 2, p. 1-16, jan./jun. 2006. Disponível em: $<$ http://server01.bc.unicamp.br/seer/ojs/viewarticle.php?id=72\&layout=html>. Acesso em: 15 fev. 2007.

BRASIL. Ministério da Educação. Coordenação de Aperfeiçoamento de Pessoal de Nível Superior. Portal.Periódicos.CAPES. Web of Knowledge. 2008. Disponível em: <www.periodicos.capes.gov.br/portugues/documentos/apresentacoes/CAPES0608.ppt>. Acesso em: 24 jun. 2008. 
BUENO, S. B.; BLATTMANN, U. Fontes de informação on-line no contexto da área de Ciências da Saúde. Revista Digital de Biblioteconomia e Ciência da Informação, Campinas, v. 2, n. 2, p. 1-17, jan./jun. 2005. Disponível em: $<$ http://eprints.rclis.org/archive/00004169/01/Silvana.pdf>. Acesso em: 23 jan. 2007.

CASTRO, C. A.; RIBEIRO, M. S. P. As contradições da sociedade da informação e a formação do bibliotecário. Revista Digital de Biblioteconomia e Ciência da Informação, Campinas, v. 1, n. 2, p. 41-52, jan./jun. 2004. Disponível em: $<$ http://server01.bc.unicamp.br/seer/ojs/viewarticle.php?id=16>. Acesso em: 23 jan. 2007.

CRUZ, A. C. O mercado de trabalho está crescendo para os bibliotecários. Gazeta Mercantil, São Paulo, 26 mar. 2001, Notícia, p. 3.

ELSEVIER. EMBASE. 2008a. Disponível em: <www.embase.com>. Acesso em: 24 jun. 2008.

ELSEVIER. SCOPUS. 2008b. Disponível em: <www.scopus.com>. Acesso em: 24 jun. 2008.

FAPESP. BIREME. SciELO: Scientific Electronic Library Online. 2008. Disponível em: <www.scielo.br>. Acesso em: 24 jun. 2008.

FERREIRA, D. T. Profissional da informação: perfil de habilidades demandadas pelo mercado de trabalho. Ciência da Informação, Brasília, v. 32, n. 1, p. 42-49, jan./abr. 2003.

FUNDAÇÃO DO DESENVOLVIMENTO ADMINISTRATIVO (FUNDAP). Programa de Aprimoramento Profissional (PAP): instruções para o credenciamento/recredenciamento de programas. São Paulo: FUNDAP, 2006.

MAIA, M. E.; ALBUQUERQUE, M. E. B. C. Sobre o projeto político pedagógico: a flexibilização curricular. Encontros Bibli: Revista Eletrônica de Biblioteconomia e 
Ciência da Informação, Florianópolis, n. 22, 2006. Disponível em: <http://www.encontros-bibli.ufsc.br/Edicao_22/maia.pdf>. Acesso em: 25 maio 2007.

MAIS um degrau. Pesquisa FAPESP, São Paulo, n. 126, p. 28, ago. 2006.

MARTINS, C. A.; KAVANAMI, R. M. M.; FANANI, A. Competências, habilidades e saberes necessários a um bibliotecário de Ciências da Saúde para recuperação de informações eletrônicas. In: CONGRESSO BRASILEIRO DE BIBLIOTECONOMIA, DOCUMENTAÇÃO E CIÊNCIA DA INFORMAÇÃO, 22. , 2007, Brasília. Anais... Brasília, 2007.

MEDEIROS, R. Educação continuada como parte da formação do profissional bibliotecário: uma ação estruturante. Revista Brasileira de Biblioteconomia e Documentação, São Paulo, v. 2, n. 1, p. 105-114, jan./jun. 2006.

OSÓRIO, M. A. L.; ALFANO, M. C. Trabalhando na biblioteca: manual para os auxiliares das bibliotecas de instituições teológicas evangélicas. São Paulo: Instituto Mackenzie, 1994. v.1.

PINTO, R. R.; IOCHIDA, L. C. O profissional da informação em Ciências da Saúde. In: CONGRESSO MUNDIAL DE INFORMAÇÃO EM SAÚDE E BIBLIOTECAS, 9., 2005, Salvador. Anais... Salvador, 2005. Disponível em: <http://www.icml9.org/program/track9/public/documents/Rosemeire\%20Rocha\%20Pin to-110307.doc> Acesso em: 05 fev. 2007.

SILVA, E. L.; CUNHA, M. V. A formação profissional no século XXI: desafios e dilemas. Ciência da Informação, Brasília, v. 31, n. 3, p. 77-82, set./dez. 2002. Disponível em: <www.scielo.br/pdf/ci/v31n3/a08v31n3.pdf>. Acesso em: 09 mar. 2005.

SOUZA, F. C. Ensina-se corretamente o que se ensina a quem vai ser bibliotecário? Revista ACB: Biblioteconomia em Santa Catarina, Florianópolis, v. 1, n. 1, p. 49-54, 1996. 
TARAPANOFF, K.; SUAIDEN, E.; OLIVEIRA, C. L. Funções sociais e oportunidades para profissionais da informação. DataGramaZero, Rio de Janeiro, v. 3, n. 5, 2002. Disponível em: <http://www.datagramazero.org.br/out02/Art_04.htm>. Acesso em: 10 dez. 2004.

UNITED STATES. National Library of Medicine. National Institutes of Health. PUBMED. 2008. Disponível em: <www.pubmed.gov>. Acesso em: 24 jun. 2008

VALENTIM, M. L. P. Atuação e perspectivas profissionais para o Profissional da Informação. In: . (Org.). Profissionais da informação: formação, perfil e atuação profissional. São Paulo: Polis, 2000a. p.135-152.

. O moderno profissional da informação: formação e perspectiva profissional.

Encontros Bibli, Santa Catarina, n. 9, jun. 2000. Disponível em: <http://www.encontros-bibli.ufsc.br/Edicao_9/marta.html>. Acesso em: 20 jun. 2008.

\section{Cláudia Araujo Martins}

Graduada em Biblioteconomia pela UNESP-Marília. Bibliotecária-chefe da FAMERP (Faculdade de Medicina de São José do Rio Preto). Mestranda em Ciências da Saúde na FAMERP. claudia@famerp.br

\section{Recebido em: 01/08/2007}

Aceito para publicação em: jan/2008 